\title{
ASNC's thoughts on the AHA/ACC chest pain guidelines
}

\author{
Randall C. Thompson, MD, MASNC, a Mouaz H. Al-Mallah, MD, FASNC, \\ Rob S. B. Beanlands, MD, MASNC, ${ }^{c}$ Dennis A. Calnon, MD, MASNC, ${ }^{d}$

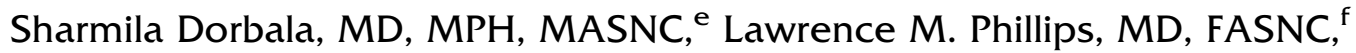 \\ Donna M. Polk, MD, MPH, FASNC, ${ }^{\text {and }}$ arem Soman, MD, PhD, MASNC ${ }^{g}$ for \\ the ASNC Board of Directors \\ a St. Luke's Mid America Heart Institute and University of Missouri-Kansas City, Kansas City, MO \\ b Cardiology, Houston Methodist Hospital, Houston, TX \\ c Division of Cardiology, Department of Medicine, University of Ottawa Heart Institute, Ottawa, \\ Canada \\ d OhioHealth Heart \& Vascular Physicians, Columbus, $\mathrm{OH}$ \\ e Brigham \& Women's Hospital, Boston, MA \\ f Division of Cardiology, NYU Langone Medical Center, New York, NY \\ g University of Pittsburgh Medical Center, Pittsburgh, PA
}

Received Oct 27, 2021; accepted Oct 27, 2021

doi: $10.1007 / \mathrm{s} 12350-021-02856-8$

This week the American Heart Association and the American College of Cardiology published the 2021 AHA/ACC/ASE/SAEM/SCCT/SCMR Guideline for the Evaluation and Diagnosis of Chest Pain. ${ }^{1}$ Guidelines on the care of patients with chest pain have been greatly needed for some time to reflect significant changes in the evidence base and technological advances in this field. After thoughtful deliberation, however, the Board of Directors of the American Society of Nuclear Cardiology (ASNC) determined that the Society could not endorse the guideline because the majority of Board members were of the opinion that important parts of the document do not support the principle of Patient First Imaging.

The new guideline was developed over several years with the input of representatives from many cardiovascular organizations with the usual debate and compromise necessary to develop recommendations on a topic as complex and controversial as chest pain. We recognize the excellent work of Renee Bullock-Palmer, MD, FASNC who was ASNC's representative on the guideline-writing committee as well as Prem Soman,

\footnotetext{
Reprint requests: Randall C. Thompson, MD, MASNC, St. Luke's Mid America Heart Institute and University of Missouri-Kansas City, Kansas City, MO; rthompson@saint-lukes.org J Nucl Cardiol 2022;29:19-23. $1071-3581 / \$ 34.00$

Copyright (c) 2021 American Society of Nuclear Cardiology.
}

MD, PhD, MASNC and Mouaz Al-Mallah, MD, FASNC who were ASNC reviewers. They served as evidence-based advocates showing the important role that nuclear cardiology plays in the evaluation of patients with chest pain. In the end, however, our review of the guidelines did not cross the threshold we felt was needed to be truly patient centered.

\section{WHY THE ASNC BOARD OF DIRECTORS VOTED NOT TO ENDORSE THESE GUIDELINES}

On two occasions in the spring and summer of this year the ASNC Board of Directors had extensive deliberations on the pros and cons of the guideline document and whether ASNC should endorse. Although the members of the Board of Directors appreciated a number of positive things about this document and appreciated the collaborative effort on the part of ACC and AHA leadership, the Board ultimately concluded that the shortcomings were too great to warrant endorsement.

We want to be clear: There are many excellent, evidence-based recommendations in the new guideline. There also are some troubling recommendations and some omissions that, in the end, ASNC cannot support. Here we explain in detail some of what is right and wrong about the new guideline as well as how practitioners like us should move forward. We will begin with what is right about the guideline. 


\section{THE POSITIVE}

The following are important strengths of the new guideline many of which were enabled by recommendations from your ASNC Board of Directors and our ASNC representatives and reviewers.

First, SPECT myocardial perfusion imaging continues to be recognized as a useful tool in the management of numerous categories of patients with chest pain. The advantages of SPECT are very reasonably highlighted. SPECT MPI appropriately has Level 1 Category of Recommendation (LOR) for intermediate-risk patients with acute or chronic chest pain and no known CAD who are eligible for cardiac testing, those who have inconclusive results on CCTA, and patients with prior CABG surgery presenting with acute chest pain who do not have ACS. ${ }^{1}$

There is a Level 2A LOR for intermediate-risk patients with acute chest pain with known CAD who have new onset or worsening symptoms and for those with prior bypass surgery or known nonobstructive CAD presenting with stable chest pain symptoms. Also, in the table on "Choosing the Right Diagnostic Test" stress testing is appropriately noted as preferred over coronary CTA when patients have intermediate to high pretest likelihood of CAD, are older, or when obstructive CAD is more highly suspected. Stress testing is also preferred if LV scar or microvascular dysfunction is suspected. ${ }^{1}$ The value of attenuation correction for SPECT and the value of the addition of CAC testing to SPECT were also acknowledged for patients with intermediate-high risk and stable chest pain, receiving LOR $2 \mathrm{~B}$ and $2 \mathrm{~A}$, respectively. ${ }^{1}$

Also, the prognostic value of PET myocardial perfusion imaging and the advantages of PET myocardial blood flow are discussed and PET MPI earned a LOR of $2 \mathrm{~A}$ as reasonable in preference to SPECT to improve diagnostic accuracy and decrease the rate of non-diagnostic test results in intermediate-high risk patients with stable chest pain. In addition, PET MPI with myocardial blood flow reserve (MBFR) is considered reasonable (LOR 2A) to diagnose microvascular dysfunction and enhance risk stratification in patients with stable chest pain and non-obstructive CAD. ${ }^{1} \mathrm{We}$ are very pleased that the guideline writers recognized both the superior prognostic power of PET MPI and PET myocardial blood flow ${ }^{2-4}$ as well as the continued strong role of SPECT in informing day-to-day patient management. Many of the key points that we applaud were not present in earlier iterations of the document. This is an example of ASNC working for our members. The input of our ASNC representatives and other ASNC members in the process was substantial and greatly improved the document.

\section{UNRESOLVED CONCERNS WITH THE NEW CHEST PAIN GUIDELINES}

Despite the many important and helpful recommendations in the new guideline, there are several recommendations that we could not support. It's important for everyone to know that ASNC communicated all of these concerns during the guideline writing and review process. Unfortunately, these problems were not all adequately addressed.

\section{FFR-CT was Given an Inappropriately Large Role in These Guidelines}

A major concern that many members of the Board of Directors expressed was the oversized role given to FFR-CT, especially given the limited availability, efficacy, level of adoption, substantial cost, and inconsistent insurance coverage. FFR-CT was given a LOR of $2 \mathrm{~A}$ in four categories of patients with chest pain and appeared prominently in multiple flow charts. ${ }^{1}$

While FFR-CT can improve the specificity of coronary CTA, its overall diagnostic accuracy is still low. ${ }^{5-7}$ For example, when FFR-CT was compared headto-head to SPECT and PET in a post-hoc analysis of the PACIFIC trial, its diagnostic accuracy was only $70 \%$ on per-patient analysis in comparison to $76 \%$ for SPECT and $86 \%$ for PET. $^{7}$ Also, the prognostic value of FFR$\mathrm{CT}$ is limited to few relatively small studies. In addition, the value of FFR-CT for coronary lesions that are in the range of $40 \%-70 \%$ remains disputed. ${ }^{8,9}$ In a study of high-risk patients after CCTA, FFR-CT does not appear to offer as much incremental prognostic value as SPECT MPI does. ${ }^{9}$ A coronary lesion that is anatomically in the range of $40 \%-70 \%$, of course, is where the accuracy of the quantitative measurements such as FFR-CT would be most needed.

There is also the issue of availability. Currently, only one company provides FFR-CT and the service is reported to the Centers for Medicare and Medicaid Services (CMS) utilizing a temporary CPT Category III code that is reserved for emerging technologies. Myocardial perfusion imaging is dramatically more available, currently being performed hundreds of times more frequently than FFR-CT. The guideline document also recommends FFR-CT in patients with equivocal coronary CT angiograms, but does not define what is equivocal. In addition, we were surprised by the lack of equipoise with no mention of the cost or limitations of FFR-CT. ${ }^{10}$ However, the limitations of other modalities are indeed outlined in tables, and sometimes without caveats that should have been included. For example, possible bronchospastic lung disease might be a contraindication for some pharmacologic stress agents but 
not for others and oral dipyridamole is not a contraindication for intravenous dipyridamole stress testing. ${ }^{11}$

\section{Greater Emphasis was Needed for Patient First Imaging}

ASNC strongly endorses the concept of patient first imaging. ${ }^{12,13}$ No one test is perfect for all patients. The decision about which test to order can be a nuanced one and cardiac imaging tests tend to be complementary. Very careful patient selection is needed and physician and technical local expertise, availability, quality of equipment, and patient preference are extremely important factors to consider. ${ }^{14}$ There is not enough emphasis on this important point, and it is hard to capture this concept in flow charts. This is an important limitation of the guideline. The key concept of patient preference, in particular, is just now beginning to receive appropriate attention. ${ }^{15,16}$ ASNC also stands for high-quality testing. It should be emphasized that high-quality imaging is patient first imaging. Although it might be hard to quantify this concept so that payers and inexperienced care givers understand the importance of this issue, we believe the guideline could have gone further in stressing this point.

\section{Greater Emphasis was Needed on the Benefits of Multimodality Testing and Risk Score Issue}

While the AHA/ACC chest pain guideline mentions the concept of combining coronary calcium scoring with functional testing, there is inadequate discussion of the benefit of this approach, one that is growing in the nuclear cardiology community. ASNC embraces multimodality imaging and this combination has advantages of identifying which patients with normal myocardial perfusion have preclinical coronary artery disease that warrants aggressive risk factor modification and close clinical follow-up. The combination of MPI with coronary calcium assessment also improves the diagnostic accuracy and strengthens the prognostic power of myocardial perfusion imaging. ${ }^{17,18}$ A major component of the prognostic power of a coronary CT angiogram rests in the identification of coronary calcifications ${ }^{4,19}$ and coronary calcium scores can be readily obtained on many inexpensive CT scanners as well as on SPECTCT and PET-CT instrumentation, while visually estimated coronary calcium scores can be obtained on an even larger number of non-gated chest CT scans. ${ }^{20}$

A less critical point of criticism of the AHA/ACC chest pain document is the method for determining low likelihood vs risk: risk scores. This concept is useful in the hospitalized patient, but not as useful in the clinic setting: The guideline goes into a lot of detail about risk scores that were developed in hospital facility patients, but these are not as helpful in the office setting where risks tend to be lower and where the majority of cardiovascular diagnostic tests are ordered.

\section{All Stress Testing Modalities Should Not Be Lumped Together}

One important procedural issue that has become particularly apparent is that it is no longer appropriate to bundle all types of stress testing together. All stress imaging tests have their unique advantages and limitations, and there are important differences in sensitivity and specificity and strengths and limitations between exercise ECG, stress echo, SPECT MPI, PET MPI and stress MRI. The concept of the dichotomy of functional testing versus anatomic testing is a common theme in the guideline in many important patient groups. This approach runs the risk of (a) giving over-emphasis to coronary CT angiography and (b) blurring distinction between different types of functional tests. Practicing cardiologists consider the advantages and limitations of all available diagnostic tests and their appropriateness for an individual patient. Indeed, the decision regarding which test to order can depend upon many factors including specific patient characteristics, local expertise (equipment and staff), local access and availability and patient preferences. Unfortunately, these considerations were not emphasized in the guideline.

\section{We Have Concerns About Unintended Effect on Payers and Potential Test Substitution}

Documents such as the AHA/ACC chest pain guideline are not only used by physicians to inform practice but are also utilized by private payers and radiology benefits management companies to develop or inform coverage and payment policies. Unfortunately for the individual patient, these guidelines could be used to selectively "cherry pick" tests. ${ }^{14,21}$ Thus, some of the imperfections of the chest pain guideline document might be amplified if the document is misused in this way. ASNC strongly opposes test substitution policies. ${ }^{14}$ We believe the expert physician should lead the decision making in collaboration with the patient and in the context of appropriate use. 


\section{NOW WHAT? HOW SHOULD WE MANAGE OUR CHEST PAIN PATIENTS?}

ASNC is committed to providing the nuclear cardiology community with the information, education and resources needed to deliver high-quality patient care. So, what does ASNC's decision not to endorse the new chest pain guideline mean for you and your practice?

Answering this question in a meaningful, actionable way is a priority. Over the coming weeks and months ASNC will offer a series of webinars and other programs that address specific patient populations and dilemmas in practice in order to discuss practical approaches. In addition, we will enhance our focus on programs to address quality and efficiency to support a patient-first approach to imaging. We encourage you to attend as many of these programs as possible.

ASNC is leading a multipronged effort to broaden the discussion about the importance of keeping the patient first. ASNC is, and always has been, a patient first organization. ASNC's priority is, and always will be, the patient, not the test. This concept is being communicated by written documents and webinars through ASNC's \#PatientFirst initiative. Toolkits are available on the ASNC website to help our members communicate with referring physicians and to appeal restrictive coverage policies. Lifelong learning is extremely important and ASNC has long embraced our mission to educate physicians in all aspects of quality imaging. ASNC takes this mission very seriously and is continuously working to support our members in performing nuclear cardiology at the highest level. When done so, myocardial perfusion imaging is very often the right test for the patient at the right time.

\section{CONCLUSION}

Despite ASNC's policy of collaboration and inclusivity and its long track record of collaborative guideline development, we are unable to endorse the current AHA/ACC Guideline for the Evaluation and Diagnosis of Chest Pain. The lack of balance in the document's presentation of the science on FFR-CT and its inappropriately prominent endorsement detract from ASNC's core principle of patient first imaging. We believe that the document fails to provide unbiased guidance to healthcare professionals on the optimal evaluation of patients with chest pain.

\section{Disclosures}

Dr. Beanlands-Consultant and Research Grants-GE Healthcare, Lantheus Medical Imaging and Jubilant DRAX-
Image; Dr. Dorbala-Honoraria and Research Grants-Pfizer and GE Healthcare; Dr. Phillips-Consultant-NovoNordisk; Dr. Soman-Consultant and Advisory Board-Pfizer, Alnylam, Eidos, Spectrum Dynamics and Research Grants-Astellas and Pfizer. The remaining authors have no relevant disclosures.

\section{References}

1. Gulati M, Levy PD, Mukherjee D, et al. 2021 AHA/ACC/ASE/ CHEST/SAEM/SCCT/SCMR guideline for the evaluation and diagnosis of chest pain: A report of the American College of Cardiology/American Heart Association Joint Committee on Clinical Practice Guidelines. J Am Coll Cardiol 2021. https://doi. org/10.1016/j.jacc.2021.07.053.

2. Bateman TM, Heller GV, Beanlands R, Calnon DA, Case J, deKemp R. Practical guide for interpreting and reporting cardiac PET measurements of myocardial blood flow: An Information Statement from the American Society of Nuclear Cardiology, and the Society of Nuclear Medicine and Molecular Imaging. J Nucl Cardiol 2021;28:768-87. https://doi.org/10.1007/s12350-021-025 52-7.

3. Patel KK, Spertus JA, Chan PS, Sperry BW, Al Badarin F, Kennedy $\mathrm{KF}$, et al. Myocardial blood flow reserve assessed by positron emission tomography myocardial perfusion imaging identifies patients with a survival benefit from early revascularization. Eur Heart J 2020;41:759-68. https://doi.org/10.1093/eurheartj/ehz389.

4. Aljizeeri A, Ahmed AI, Alfaris MA, Ahmed D, Farea J, Elneama A, et al. Myocardial flow reserve and coronary calcification in prognosis of patients with suspected coronary artery disease. JACC Cardiovasc Imaging 2021. https://doi.org/10.1016/j.jcmg. 2021.01.024.

5. Douglas PS, Pontone G, Hlatky MA, Patel MR, Norgaard BL, Byrne RA, et al. Clinical outcomes of fractional flow reserve by computed tomographic angiography-guided diagnostic strategies vs. usual care in patients with suspected coronary artery disease: The prospective longitudinal trial of $\mathrm{FFR}(\mathrm{CT})$ : Outcome and resource impacts study. Eur Heart J 2015;36:3359-67. https://doi. org/10.1093/eurheartj/ehv444.

6. Douglas PS, De Bruyne B, Pontone G, et al. 1-Year outcomes of FFRCT-guided care in patients with suspected coronary disease: The PLATFORM Study. J Am Coll Cardiol 2016;68:435-45.

7. Driessen RS, Danad I, Stuijfzand WJ, Raijmakers PG, Schumacher SP, van Diemen PA, et al. Comparison of coronary computed tomography angiography, fractional flow reserve, and perfusion imaging for ischemia diagnosis. J Am Coll Cardiol 2019;73:161-73. https://doi.org/10.1016/j.jacc.2018.10.056.

8. Kruk M, Wardziak $Ł$, Demkow M, et al. Workstation-based calculation of CTA-based FFR for intermediate stenosis. JACC Cardiovasc Imaging 2016;9:690-9.

9. Ahmed AI, Han Y, Al Rifai M, Alnabelsi T, Nabi F, Chang SM, et al. Prognostic value of computed tomography-derived fractional flow reserve comparison with myocardial perfusion imaging. JACC Cardiovasc Imaging 2021. https://doi.org/10.1016/j.jcmg. 2021.09.007.

10. Food and Drug Administration De Novo Classification request for FFR $_{\mathrm{CT}}$ v. 1.4. Accessed November 9, 2021 at https://www.acce ssdata.fda.gov/cdrh_docs/reviews/DEN130045.pdf.

11. Henzlova MJ, Duvall WL, Einstein AJ, Travin MI, Verberne HJ. ASNC imaging guidelines for SPECT nuclear cardiology procedures: Stress, protocols, and tracers. J Nucl Cardiol 2016;23:60639. https://doi.org/10.1007/s12350-015-0387-x. 
12. Thompson RC. ASNC President's Message. ASNC stands for \#PatientFirst imaging. J Nucl Cardiol 2021;28:788-789. https://d oi.org/10.1007/s12350-021-02571-4.

13. Thompson RC, Calnon DA, Polk DM, Al-Mallah MH, Phillips LM, Dorbala S, Beanlands RSB. ASNC statements of principles on the issue of multimodality imaging. J Nucl Cardiol (2021). h ttps://doi.org/10.1007/s12350-021-02793-6.

14. Thompson RC, Bateman TM, Blankstein R, Di Carli MF, Heydari $\mathrm{B}$, Hung J, et al. A policy statement on cardiovascular test substitution and authorization: Principles of patient-centered noninvasive testing. J Am Coll Cardiol 2021;78:1385-9. https://d oi.org/10.1016/j.jacc.2021.07.043.

15. Golden KE, Chang AM, Hollander JE. Sex preferences in cardiovascular testing: The contribution of the patient-physician discussion. Acad Emerg Med 2013;20:680-8.

16. Porath JD, Meka AP, Morrow C, et al. Patient preferences for diagnostic testing in the emergency department: A cross-sectional study. Acad Emerg Med 2018;25:627-33.

17. Nappi C, Nicolai E, Daniele S, Acampa W, Gaudieri V, Assante R, et al. Long-term prognostic value of coronary artery calcium scanning, coronary computed tomographic angiography and stress myocardial perfusion imaging in patients with suspected coronary artery disease. J Nucl Cardiol 2018;25:833-41. https://doi.org/10. 1007/s12350-016-0657-2.

18. Chang SM, Nabi F, Xu J, Peterson LE, Achari A, Pratt CM, et al. The coronary artery calcium score and stress myocardial perfusion imaging provide independent and complementary prediction of cardiac risk. J Am Coll Cardiol 2009;54:1872-82. https://doi.org/ 10.1016/j.jacc.2009.05.071.

19. Mortensen MB, Dzaye O, Steffensen FH, Bøtker HE, Jensen JM, Rønnow Sand NP, et al. Impact of plaque burden versus stenosis on ischemic events in patients with coronary atherosclerosis. J Am Coll Cardiol 2020;76:2803-13. https://doi.org/10.1016/j.jacc.2020. 10.021 .

20. Trpkov C, Savtchenko A, Liang Z, Feng P, Southern DA, Wilton $\mathrm{SB}$, et al. Visually estimated coronary artery calcium score improves SPECT-MPI risk stratification. Int J Cardiol Heart Vasc 2021;35:100827. https://doi.org/10.1016/j.ijcha.2021.100827.

21. Young GP, Lowe RA. Adverse outcomes of managed care gatekeeping. Acad Emerg Med 1997;4:1129-36.

Publisher's Note Springer Nature remains neutral with regard to jurisdictional claims in published maps and institutional affiliations. 